\title{
BMJ Open Breast feeding and infant development in a cohort with sibling pair analysis: the Japan Environment and Children's Study
}

\author{
Masafumi Sanefuji (D) ,1,2 Ayako Senju, ${ }^{3,4}$ Masayuki Shimono, ${ }^{3,4}$ \\ Masanobu Ogawa, ${ }^{1,5}$ Yuri Sonoda, ${ }^{1,2}$ Michiko Torio, ${ }^{2}$ Yuko Ichimiya, ${ }^{2}$ Reiko Suga, ${ }^{4}$ \\ Yasunari Sakai (D) , ${ }^{2}$ Satoshi Honjo, ${ }^{6}$ Koichi Kusuhara, ${ }^{3,4}$ Shouichi Ohga, ${ }^{1,2}$ Japan \\ Environment and Children's Study Group
}

To cite: Sanefuji M, Senju A, Shimono M, et al. Breast feeding and infant development in a cohort with sibling pair analysis: the Japan Environment and Children's Study. BMJ Open 2021;11:e043202. doi:10.1136/ bmjopen-2020-043202

- Prepublication history and additional supplemental material for this paper are available online. To view these files, please visit the journal online. (http://dx.doi.org/10.1136/ bmjopen-2020-043202)

Received 29 July 2020 Accepted 29 July 2021

Check for updates

(C) Author(s) (or their employer(s)) 2021. Re-use permitted under CC BY-NC. No commercial re-use. See rights and permissions. Published by BMJ.

For numbered affiliations see end of article.

Correspondence to Dr Masafumi Sanefuji; sanefuji39@gmail.com

\section{ABSTRACT}

Objectives To investigate the association between breast feeding and infant development during the first year of life using sibling comparison.

Design Nationwide prospective birth cohort study with sibling pair analysis.

Setting 15 regional centres that participated in the Japan Environment and Children's Study.

Participants This study included 77119 children (singleton, term birth and no malformation/severe diseases) whose mothers were registered between January 2011 and March 2014, including 3521 duos or trios of siblings.

Primary outcome measures The primary outcome was developmental delay at 6 and 12 months of age, assessed using the Japanese translation of the Ages and Stages Questionnaires, third edition. Multivariable regression analyses adjusted for confounders were performed to estimate the risk ratios of delay associated with any or exclusive breast feeding. Pairs of siblings discordant for statuses were selected, and conditional regression analyses were conducted with a matched cohort design.

Results Developmental delay was identified in 6162 $(8.4 \%)$ and $10442(14.6 \%)$ children at 6 and 12 months of age, respectively. Any breast feeding continued until 6 months or 12 months old was associated with reduced developmental delay at 12 months of age (adjusted risk ratio ( $95 \% \mathrm{Cl}): 0.81$ (0.77 to 0.85 ) and 0.81 (0.78 to 0.84 ), respectively). Furthermore, exclusive breast feeding until 3 months was associated with reduced developmental delay at 12 months of age (adjusted risk ratio, 0.86 (95\% $\mathrm{Cl} 0.83$ to 0.90$)$ ). In sibling pair analysis, the association between any breast feeding until 12 months and reduced developmental delay at 12 months of age persisted (adjusted risk ratio, 0.64 (95\% $\mathrm{Cl} 0.43$ to 0.93)). Conclusions The present study demonstrated the association of continuous breast feeding with reduced developmental delay at 1 year of age using sibling pair analysis, in which unmeasured confounding factors are still present but less included. This may provide an argument to promote breastfeeding continuation.

\section{STRENGTHS AND LIMITATIONS OF THIS STUDY}

$\Rightarrow$ This study is the largest birth cohort study that investigated the association between breast feeding and infant development.

$\Rightarrow$ The association was examined using not only ordinary multivariable regression analysis but also sibling comparison, which strongly controls for sibling-shared factors.

$\Rightarrow$ Monthly feeding status was collected at child's age of 1 month, 6 and 12 months, minimising the risk of recall bias.

$\Rightarrow$ Developmental delay was determined by a parentreported screening test and thus may be equivocal.

$\Rightarrow$ The results could not eliminate the possibility that the association still could be explained by reverse causation because the reason for cessation of breast feeding was not known.

\section{INTRODUCTION}

Since 1929, the beneficial effects of breast feeding on brain development have been repeatedly demonstrated. ${ }^{1-4}$ Many observational studies ${ }^{5-8}$ demonstrate that breast feeding is associated with better cognitive outcomes, including neurodevelopment, language and intelligence. In these studies, however, the causation remains unclear because the reason for cessation of breast feeding is not known. Furthermore, this association can be produced by differences in demographic, socioeconomic and environmental factors between mothers who breastfeed and those who do not. ${ }^{9-12}$ In highincome countries, mothers with higher levels of education, social position, income and intelligence are more inclined to breastfeed and to do so more exclusively and for a longer duration. Thus, their children are more likely to have higher cognitive functions, which can result in a superficial association between 
breast feeding and better child cognition. In previous studies, the association disappeared or became highly diminished after controlling for confounders, especially maternal intelligence. ${ }^{9} 1314$ Nonetheless, a recent metaanalysis concluded that breast feeding was significantly associated with higher cognitive abilities, even after adjusting for such confounding factors. ${ }^{3}$

After explicitly controlling for these measured factors, unmeasured-even unknown-confounders such as parental characteristics and child-rearing practices remained. To further control for these confounders, previous studies ${ }^{915-17}$ conducted sibling pair analysis in investigating the association of breast feeding with child cognitive outcomes. These analyses focused on siblings pairs who were discordant for breastfeeding exposure. A sibling pair from the same mother largely shares parental and environmental factors. Thus, the effects of these confounders can be cancelled out when the pair is matched in the analysis. However, on this topic, sibling pair analysis is challenging because little variation in breast feeding often exists between siblings, which may reduce statistical power and erroneously cause null findings. ${ }^{17}$ To our knowledge, only three studies ${ }^{91516}$ have examined the association between breast feeding and cognitive functions using this method, and these studies all produced statistically null effects. The reason for the null results remains unclear. However, these findings may be accounted for by the study designs: data on feeding status were collected only once within 1 year ${ }^{9}$ or 2 years ${ }^{15}$ after a child's birth or in adolescence. ${ }^{16}$

The goal of the current study was to investigate the association between breast feeding and child development during the first year of life by using data from the Japan Environment and Children's Study (JECS). This nationwide birth cohort study includes $>100000$ children and thus enables sibling pair analysis with a sufficient number of participants. The monthly status of breast feeding was collected repeatedly in the first year of life, thereby minimising the risk of recall bias. The beneficial effects of breast feeding on cognitive development decrease as children age ${ }^{18}$; therefore, investigating the association between breast feeding and cognitive development during early childhood has the advantage of allowing researchers to infer the role of breast feeding on the developing brain.

\section{METHODS \\ Design}

The JECS is a nationwide, multicentre, prospective birth cohort study funded by the Ministry of Environment, Japan. The details of the study design have been described elsewhere. ${ }^{19}{ }^{20}$ Briefly, pregnant participants were registered between January 2011 and March 2014 in 15 regional centres covering a wide geographical area in Japan. During the pregnancy, data on demographics, smoking, alcohol, education and socioeconomic statuses were obtained during the first and second/third trimesters by using self-administered questionnaires. Detailed information regarding the mother and child was obtained from medical records transcripts during the first trimester, at the time of delivery, and when the child was 1 month. After delivery, data on feeding style, use of complementary foods, developmental status and affected diseases were collected at ages 1 and 6 months and every 6 months until the child was 6 years old, and then twice a year thereafter via self-reported questionnaires completed by the parents.

\section{Participants}

In this study, we used the fixed dataset 'jecs-an-20180131' that was released in March 2018. This dataset contains all available data extracted from the aforementioned questionnaires and records until a child was 12 months old. The data for 104065 fetuses from 103062 pregnancies were linked to the respective maternal data. The participants selected were 92381 live-born singleton children, delivered at term $(\geq 37$ gestational weeks and $<42$ gestational weeks), of parents of Japanese nationality and for whom information on sex and birth weight had been recorded (figure 1). Of these children, those who had malformations or severe diseases, or who had missing information on feeding style during the first year of life or development at 6 months and 12 months old were excluded. After these exclusions, the data of 77119 children were included in our analysis.

\section{Exposure}

The main exposure factor was breast feeding. Mothers were asked to fill in the monthly feeding status of their child by using questionnaires when the child was 1 month, 6 months and 12 months old. This information included whether the child was breastfed, formula fed or both. The questionnaire administered when the child was 12 months old also queried when complementary food was first started. Breastfeeding duration indicated how long a child was breastfed from birth, irrespective of concurrent consumption of formula milk. We also dichotomously assessed whether or not a child continued (1) any breast feeding until 6 months old, (2) any breast feeding until 12 months, (3) exclusive breast feeding until 3 months and (4) exclusive breast feeding until 6 months. Breast feeding was 'exclusive' if the child consumed only breastmilk-and nothing else (no consumption of formula milk or complementary foods) during these periods. To gain more insight into the significance of exclusive breast feeding, we further classified the children who continued breast feeding until 6 months into four categories: (1) children who ingested neither formula milk nor complementary food (exclusive breast feeding), (2) those who ingested formula but not complementary food, (3) those who ingested complementary food but not formula and (4) those who ingested both formula and complementary food, at any time during the period.

For sibling pair analysis, we selected pairs who were discordant on the status of any breast feeding or exclusive 


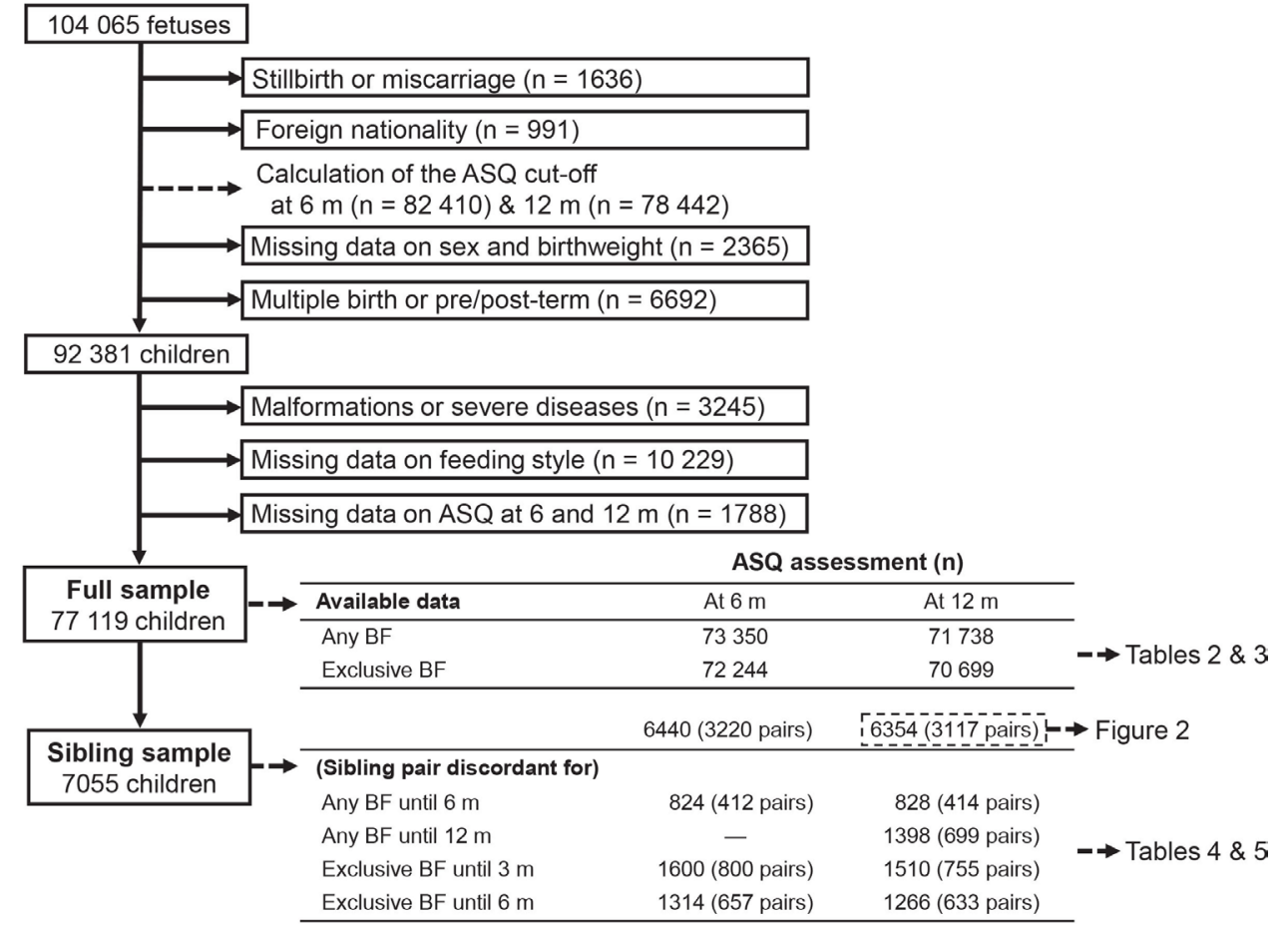

Figure 1 Flow chart of participant selection. ASQ, Ages and Stages Questionnaires; BF, breast feeding.

breast feeding. When discordance was observed among three siblings (eg, only one of the three children was breastfed), we randomly selected one of the two siblings who were not breastfed and then paired the selected one with the breastfed sibling.

\section{Outcome}

The outcome was developmental delay measured at 6 months and 12 months old, using the Japanese translated version of the Ages and Stages Questionnaires (ASQ): A Parent-Completed Monitoring System, third edition. This version was prepared through a back-translation procedure and was approved by the publisher of the original English version. ${ }^{21}$ The ASQ can identify infants or young children who need further developmental assessment to determine whether they are eligible for early intervention. The findings of the questionnaire basically agree with those of professionally administered developmental batteries. ${ }^{22} 23$ It has been used in clinical and research settings and translated into several languages. ${ }^{24-27}$ The ASQ assesses five developmental domains. For each domain, six skills are described to which parents answer 'yes,' 'sometimes,' or 'not yet,' depending on whether their child is demonstrating the described skill. The responses are converted to points, with 'yes' receiving 10 points; 'sometimes', 5 points and 'not yet', 0 points. The child's score for each developmental domain is the sum of all points received for the items under that domain and ranges from 0 to 60 points. The cut-off score for each domain was defined as $2 \mathrm{SD}$ below the mean score of large standardised samples in the USA. A child was defined as having a developmental delay if a score was at or below the cut-off level in any developmental domain. When the cut-off scores of the original English version were used in our population, an excessive number of children were classified as having a developmental delay $(47.4 \%$ and $34.6 \%$ for 6 months and 12 months, respectively). Although preliminary cut-off scores of the Japanese translation were recently proposed, ${ }^{28}$ these were not recommended to be used with confidence before 24 months old because of very limited sample sizes. Therefore, the cutoff scores were determined by using the same methodologies used in the original version, based on available data at ages 6 months $(n=82410)$ and 12 months $(n=78442)$ (figure 1), which would represent the general Japanese population. As a continuous variable, in addition, total score of ASQ was defined as the sum of the scores for the five domains, ranging from 0 to 300 points.

\section{Statistical analysis}

To assess the association of breast feeding with child development, we conducted multivariable quasi-Poisson regression analyses for dichotomous dependent variables, and multiple linear regression analyses for continuous dependent variables. The adjusted covariates were (1) sex, (2) gestational age, (3) birth weight, (4) mother's age, (5) maternal smoking status during pregnancy, as recorded in the first trimester, (6) maternal alcohol consumption during pregnancy, as recorded in the second trimester, (7) maternal and (8) paternal education level (junior high school, high school and university or graduate school), (9) annual family income $(<¥ 4000$ 000; $¥ 000$ 000- $¥ 5999999 ; \geq ¥ 6000000$ ), (10) introduction of complementary foods before 6 months old and (11) home speech stimulation at 1 month (whether a mother did or did not talk to her baby habitually: yes/ 
no). The 'home speech stimulation' covariate was used instead of the Home Observation for Measurement of the Environment scale, ${ }^{29}$ which is not employed in the JECS.

For sibling pair analysis, we conducted conditional logistic regression analyses with 1:1 matched cohort data of sibling pairs whose dichotomous statuses of breast feeding were discordant. ${ }^{30}$ We reported adjusted relative risks (aRRs) with 95\% CIs that were converted from ORs using an established method. ${ }^{31}{ }^{32}$ We also used a longitudinal linear mixed model, in which fixed effects were age of ASQ assessment ( 6 vs 12 months old), duration of breast feeding and the interaction term between them, with random intercept for sibling. The adjusted covariates were as follows: (1) sex, (2) gestational age, (3) birth weight, (4) order of siblings in the discordant pair, (5) maternal smoking status, (6) maternal alcohol consumption, (7) complementary food introduction and (8) home speech stimulation at 1 month old. All statistical analyses were conducted using $\mathrm{R}$ software (V.3.5.0). In the R package, we used 'survival' (V.3.2.7) for conditional logistic regression model and 'Ime4' for longitudinal linear mixed model. The level of significance was $\mathrm{p}=0.05$.

\section{Patient and public involvement}

No participants were involved in creating the research question or the outcome measures, nor were they involved in developing plans for recruitment, design or implementation of the study. No participants were asked to provide advice on the interpretation or writing up of the results. There are plans to disseminate the results of the research to study participants and the general public. Participants were thanked in the acknowledgements.

\section{RESULTS}

The baseline characteristics of 77119 children are summarised in table 1 . Nearly all $(76167,98.8 \%)$ children were started on any breastmilk during their first month of life. Any breast feeding was continued until ages 6 and 12 months in $82.1 \%$ and $64.4 \%$ of children, respectively. Exclusive breast feeding was continued until ages 3 and 6 months in $39.6 \%$ and $20.3 \%$ of children, respectively. Developmental delay was identified in $8.4 \%$ and $14.6 \%$ of children at 6 months and 12 months old, respectively. The sibling cohort included 3521 sibling sets (7055 children) in total: 3508 duos (7016 children) and 13 trios (39 children). The characteristics of the sibling sample were substantially similar to those of the full sample. Nevertheless, the sibling sample appeared to have weak tendencies towards younger maternal age, lower paternal education, lower family income, lower rates for any breast feeding until 12 months old and higher rates for exclusive breast feeding until 3 months.

For the full sample ( $\mathrm{n}=77119)$, we conducted multivariable regression analyses, while adjusting for confounders, to examine developmental delay in relation to various types of breastfeeding exposures. When breast feeding was treated as dichotomous variables, quasi-Poisson models revealed that any breast feeding continued until 6 months was associated with reduced developmental delay at ages 6 months (aRR (95\% CI): $0.81(0.76$ to 0.86$)$ ) and 12 months $(0.81$ (0.77 to 0.85$)$ ) (table $2 \mathrm{~A})$. Any breast feeding until 12 months was similarly associated with reduced developmental delay at age 12 months $(0.81$ (95\% CI 0.78 to 0.84$)$ ). Any breast feeding was similarly continued until 12 months old between children with $(77.4 \%)$ and without developmental delay $(78.6 \%)$ at 6 months old (online supplemental figure S1), arguing against the possibility that developmental delay per se interrupted the continuation of breast feeding. When developmental delay was not observed at 6 months old, it is more likely to occur newly at 12 months in children who discontinued breast feeding by 12 months old than those continued it while delay at 6 months resolved more often in children who continued breast feeding (online supplemental figure S2). Furthermore, exclusive breast feeding that continued until 3 months old, but not until 6 months, was associated with developmental delay at age 12 months $(0.86$ (95\% CI 0.83 to 0.90$)$ ), table 2B). Among the children who continued breast feeding until 6 months old and had the information on complementary food, the effects of formula milk and complementary food was estimated, referenced to exclusive breast feeding (table 2C). The risk of developmental delay at 6 months was reduced in children who concomitantly ingested complementary food, irrespective of formula feeding. The risk of developmental delay at 12 months was increased in those who concurrently ingested formula milk without complementary food, but was reduced in those who ingested complementary food with no formula. When breast feeding duration was treated as a continuous variable, multiple linear regression model demonstrated that duration of any or exclusive breast feeding was positively associated with increased total ASQ scores at 6 and 12 months old (table 3).

To conduct sibling pair analysis, we extracted data from pairs of siblings who both underwent a developmental assessment at 6 months old (3220 pairs) and 12 months old (3117 pairs). Among these children, we further selected sibling pairs who were discordant for various breastfeeding statuses (figure 1 and table 4). Few variations existed in the statuses between pairs; therefore, the number of selected pairs was relatively small, varying from 412 pairs (824 children) to 800 pairs (1600 children), based on age (3 months, 6 months, or 12 months) and type (any breast feeding or exclusive breast feeding). Among these combinations, the adjusted conditional regression model for 699 sibling pairs (1398 children) revealed that any breast feeding until 12 months was significantly associated with reduced developmental delay at this age (0.64 (95\% CI 0.43 to 0.93$)$ ). The mean breast feeding duration was 12 months in the sibling who was continuously breastfed and $7.8 \pm 2.9$ months in the sibling who was not. Moreover, exclusive breast feeding was not significantly associated with reduced developmental delay at any age. In sibling pairs discordant for any breast 
Table 1 Baseline characteristics of the children

\begin{tabular}{|c|c|c|c|c|c|}
\hline & $\begin{array}{l}\text { Full sample ( } n=77 \\
\text { 119) }\end{array}$ & Missing & $\begin{array}{l}\text { Sibling sample } \\
(\mathrm{n}=7055)\end{array}$ & Missing & $\begin{array}{l}\text { Effect } \\
\text { size* }^{\star}\end{array}$ \\
\hline Boy, no. (\%) & $39350(51.0)$ & 0 & $3552(50.3)$ & 0 & 0.00 \\
\hline Gestational age (weeks), mean (SD) & $39.5(1.1)$ & 0 & $39.5(1.1)$ & 0 & 0.00 \\
\hline Birth weight (g), mean (SD) & $3062(365)$ & 0 & $3079(360)$ & 0 & 0.01 \\
\hline Maternal age (years), mean (SD) & $31.3(4.9)$ & 4 & $29.8(4.6)$ & 0 & 0.09 \\
\hline Maternal smoking during pregnancy, no (\%) & $12424(16.3)$ & 858 & $1062(15.2)$ & 58 & 0.01 \\
\hline Maternal alcohol during pregnancy, no (\%) & $2080(2.7)$ & 875 & $231(3.3)$ & 71 & 0.01 \\
\hline Maternal education, no. (\%) & & 700 & & 49 & 0.02 \\
\hline Junior high school & $3029(4.0)$ & & $310(4.4)$ & & \\
\hline High school & $56180(73.5)$ & & $5264(75.1)$ & & \\
\hline University/graduate school & $17210(22.5)$ & & $1432(20.4)$ & & \\
\hline Paternal education, no (\%) & & 1111 & & 62 & 0.03 \\
\hline Junior high school & $4960(6.5)$ & & $541(7.7)$ & & \\
\hline High school & $44973(59.2)$ & & $4381(62.6)$ & & \\
\hline University/graduate school & 26075 (34.3) & & $2071(29.6)$ & & \\
\hline Family income, no (\%) & & 5454 & & 427 & 0.03 \\
\hline Low (<¥4 000 000) & $28012(39.1)$ & & $2836(42.8)$ & & \\
\hline Middle ( $¥ 4000000-¥ 5999$ 999) & $24070(33.6)$ & & $2189(33.0)$ & & \\
\hline $\operatorname{High}(\geq ¥ 6000000)$ & $19583(27.3)$ & & $1603(24.2)$ & & \\
\hline Complementary food before 6 months, no (\%) & 34126 (44.9) & 1175 & $3194(45.9)$ & 95 & 0.01 \\
\hline Home speech stimulation at 1 month, no (\%) & $62400(81.1)$ & 214 & $5611(79.7)$ & 17 & 0.01 \\
\hline Any breast feeding until 1 month, no (\%) & $76167(98.8)$ & 0 & $6976(98.9)$ & 0 & 0.00 \\
\hline Any breast feeding until 6 months, no (\%) & $63296(82.1)$ & 0 & $5713(81.0)$ & 0 & 0.01 \\
\hline Any breast feeding until 12 months, no (\%) & $49672(64.4)$ & 0 & $4148(58.8)$ & 0 & 0.04 \\
\hline Exclusive breast feeding until 3 months, no (\%) & 30049 (39.6) & 1175 & $3031(43.5)$ & 95 & 0.03 \\
\hline Exclusive breast feeding until 6 months, no (\%) & $15447(20.3)$ & 1175 & $1507(21.7)$ & 95 & 0.01 \\
\hline Neurodevelopmental delay at 6 months, no (\%) & $6162(8.4)$ & 3769 & $559(8.3)$ & 322 & 0.00 \\
\hline Neurodevelopmental delay at 12 months, no (\%) & $10442(14.6)$ & 5381 & $888(13.4)$ & 443 & 0.01 \\
\hline
\end{tabular}

Effect sizes are calculated as phi/Cramer's $V$ and $r$, using $\chi^{2}$ and Student's t-tests for the categorical and numerical variables, respectively. ${ }^{*}$ The difference between sibling samples versus the rest $(n=70064)$.

feeding until 12 months, when the first-born children continued breast feeding, the second born, who discontinued it, had a tendency for developmental delay at 12 months; when the first born discontinued breast feeding, the second showed a reduced tendency (online supplemental figure S3). In sibling pairs who were discordant for maternal smoking, a proxy for socioeconomical status at that time, any breast feeding was similarly continued until 12 months old between children whose mothers had smoking $(52.9 \%)$ vs no smoking $(54.5 \%)$ during the pregnancy (online supplemental figure S4). When breast feeding was treated as continuous variables, longitudinal linear mixed model revealed that duration of any, but not exclusive, breast feeding was associated with increased total ASQ score (table 5).

To clarify how differently siblings were breastfed during the first year of life, we classified 3117 pairs whose developmental assessment at 12 months old was recorded into three groups: 'both' (both children were breastfed), 'discordant' (only one child was breastfed) and 'neither' (neither child was breastfed) (figure 2). The number of discordant pairs increased from $43(1.4 \%)$ pairs at the first month of life to $389(12.5 \%)$ pairs at 6 months and $666(21.4 \%)$ pairs at 12 months.

\section{DISCUSSION}

The present study investigated the relationship between breast feeding and child development during the first year of life. Ordinary multivariable regression analyses demonstrated that any breast feeding continued until 6 or 12 months old, and exclusive breast feeding until 3 months were significantly associated with reduced developmental delay. In the sibling pair analysis, only the association between any breast feeding until 12 months old and reduced developmental delay at 12 months old remained 


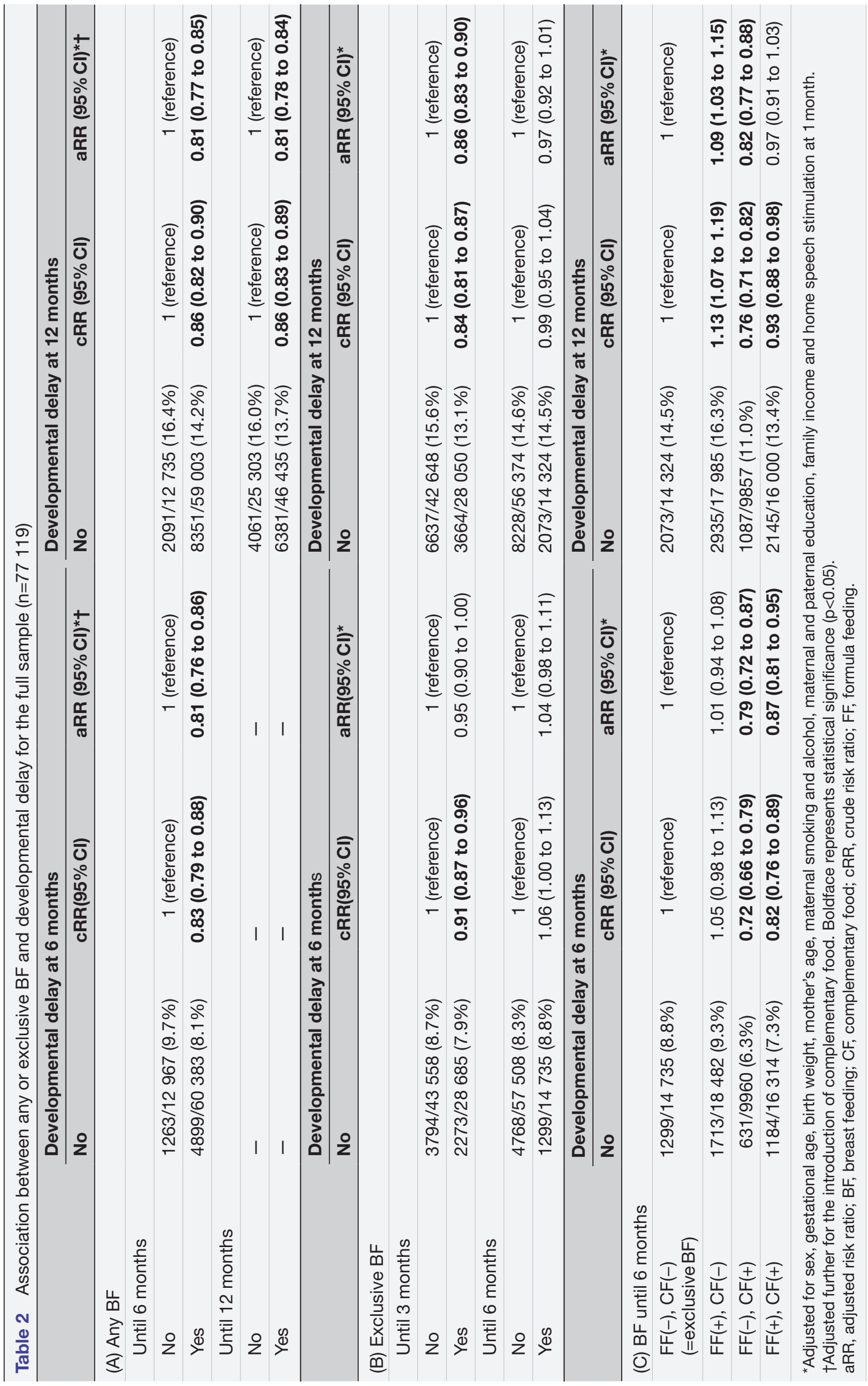

8

월 
Table 3 Association between duration of any or exclusive BF and total ASQ score for the full sample ( $n=77$ 119)

\begin{tabular}{|c|c|c|c|c|}
\hline & \multicolumn{2}{|c|}{ Increase of score at 6 months per BF month } & \multicolumn{2}{|c|}{$\begin{array}{l}\text { Increase of score at } 12 \text { months per BF } \\
\text { month }\end{array}$} \\
\hline & crude $\mathrm{B}(95 \% \mathrm{Cl})$ & adjusted $\mathrm{B}(95 \% \mathrm{Cl}) * \dagger$ & crude B $(95 \%$ Cl) & adjusted $\mathrm{B}(95 \% \mathrm{Cl}) * \dagger$ \\
\hline \multirow[t]{2}{*}{$\begin{array}{l}\text { Duration of any BF }(0-12 \\
\text { months) }\end{array}$} & - & - & $0.47(0.36$ to 0.57$)$ & 0.77 (0.65 to 0.88$)$ \\
\hline & crude B $(95 \% \mathrm{Cl})$ & adjusted $\mathrm{B}(95 \% \mathrm{Cl})^{*}$ & crude B $(95 \% \mathrm{Cl})$ & adjusted $\mathrm{B}(95 \% \mathrm{Cl})^{*}$ \\
\hline $\begin{array}{l}\text { Duration of exclusive BF }(0-6 \\
\text { months) }\end{array}$ & $0.63(0.51$ to 0.76$)$ & $0.54(0.41$ to 0.67$)$ & $0.91(0.77$ to 1.05$)$ & $0.90(0.75$ to 1.04$)$ \\
\hline \multicolumn{5}{|c|}{$\begin{array}{l}\text { *Adjusted for sex, gestational age, birth weight, mother's age, maternal smoking and alcohol, maternal and paternal education, family income } \\
\text { and home speech stimulation at } 1 \text { month. } \\
\text { †Adjusted further for the introduction of complementary food. Boldface represents statistical significance }(\mathrm{p}<0.05) \text {. } \\
\text { ASQ, Ages and Stages Questionnaires; BF, breast feeding. }\end{array}$} \\
\hline
\end{tabular}

significant. The null association of any breast feeding until 6 months might be explained by failure to detect less developmental variations at 6 months compared with those at 12 months, or involvement of other environmental factors that child had experienced after 6 months.

The association that we observed between breast feeding and brain functions has repeatedly been reported in observational, meta-analysis and randomised controlled studies. ${ }^{347833}$ In these studies, the results were heterogeneously adjusted for various parental and environmental confounders. However, no matter how many measured confounders are included, unmeasured confounding factors always exist. Hence, we opted for sibling pair analysis, which controls for all factors shared by siblings from the same mother. ${ }^{17}$ We observed a significant association between breast feeding and development at 12 months. Our findings further support the WHO's recommendations concerning continued breast feeding beyond 6 months old. ${ }^{2}$ The reason for our significant results is unlikely to be explained simply by the sufficient number of our discordant pairs of siblings (1398 children), which is comparable to the number in previous studies $^{9} 1516$ reporting null findings (1046, 1090 and 1773 children). A possible explanation is that we assessed child's development in the first year of life, whereas the previous studies assessed it at 4-14 years. A randomised control study showed that the beneficial effects of breastmilk on cognitive development decrease with advancing age; thus, other environmental and genetic factors may become more important as children age. ${ }^{18}$

The mechanisms underlying the association between breast feeding and brain development are unclear but may be attributable to its nutrients such as long-chain polyunsaturated fatty acids, hormones and cytokines. ${ }^{34} 35$ Another probable mechanism is mother-infant interaction produced by breast feeding behaviours. ${ }^{36}$ A series of Family Nurture Intervention study have repeatedly demonstrated the importance of early nurturing activities that engage the mother and infant reciprocally in physical, sensory and emotional experiences in infant development. ${ }^{37-43}$ Such nurturing activities via breast feeding may enhance the connection between social motivation and mother-infant relational health, ${ }^{44}$ leading to better development.

In contrast to any breast feeding, exclusive breast feeding had no significant association with developmental delay in our study. Research on the association between exclusive breast feeding and cognitive development is relatively scarce and has yielded inconsistent results: some studies report positive effects of exclusive breast feeding on neurodevelopment, ${ }^{45} 46$ whereas other studies report limited or rather negative effects. ${ }^{47-49}$ The reason for the reduced effects of exclusive breast feeding versus that of any breast feeding is not well understood. Our results showed that concomitant ingestion of complementary food, but not formula milk, was associated with reduced developmental delay in the children who continued breast feeding until 6 months old (table 2C). Thus, breastmilk without supplementation of complementary food may not meet the full requirements for energy and micronutrients such as iron and zinc, which all have important roles in the developing brain, ${ }^{50}$ of the average infant at 6 months old, as some researchers suggested. ${ }^{51}$ Withholding complementary food until age 6 months may negate the beneficial effects of breast feeding. Alternatively, such withholding might reflect some unmeasured confounders that adversely related to infant development.

In this study, a number of pairs who were discordantly breastfed in the first year of life increased with age, with the least discordance being at 1 month old, at which point $98.2 \%$ of the sibling pairs were both breastfed. This finding suggests that most mothers breastfeed their children in early infancy but discontinue later at different 


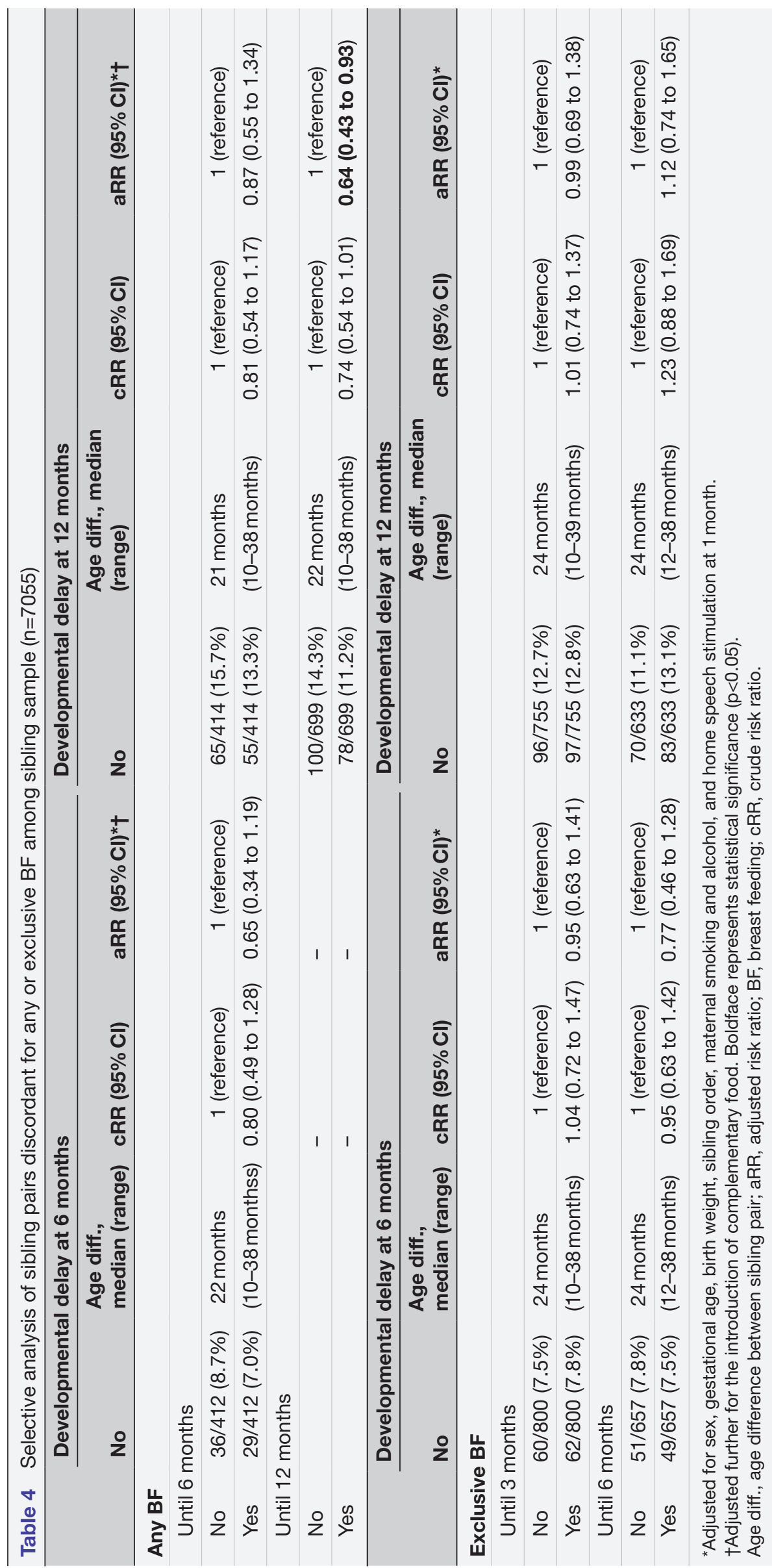


Table 5 Association between duration of any or exclusive BF and total ASQ score for sibling sample $(n=7055)$

\begin{tabular}{|c|c|c|}
\hline & \multicolumn{2}{|c|}{ Increase of score per BF month } \\
\hline & Crude B (95\% Cl) & Adjusted B $(95 \% \mathrm{Cl})^{*} \dagger$ \\
\hline ASQ age (6 months (0) vs 12 months (1)) & $12.8(11.7$ to 14.0$)$ & $12.9(11.8$ to 14.1$)$ \\
\hline \multirow[t]{2}{*}{ ASQ age $\times$ duration of any BF } & $-0.57(-1.69$ to 0.55$)$ & $-0.40(-1.53$ to 0.73$)$ \\
\hline & \multicolumn{2}{|c|}{ Increase of score per BF month } \\
\hline ASQ age (6 months (0) vs 12 months (1)) & $12.9(11.7$ to 14.0$)$ & $12.9(11.8$ to 14.1$)$ \\
\hline Duration of exclusive BF (0-6 months) & $1.00(-0.15$ to 2.15$)$ & $1.14(-0.01$ to 2.28$)$ \\
\hline ASQ age $\times$ duration of exclusive $B F$ & $0.65(-0.48$ to 1.77$)$ & $0.65(-0.48$ to 1.78$)$ \\
\hline
\end{tabular}

*Adjusted for sex, gestational age, birth weight, sibling order, maternal smoking and alcohol, and home speech stimulation at 1 month. †Adjusted further for the introduction of complementary food. Boldface represents statistical significance $(p<0.05)$.

ASQ, Ages and Stages Questionnaires; BF, breast feeding.

times for each sibling. Thus, the association between breast feeding and development is likely related more to breast feeding late into year 1 rather than breast feeding early. By contrast, a previous randomised controlled trial ${ }^{33}$ in which participants were randomly assigned to a breastfeeding promotion intervention group demonstrated that discordance in breast feeding between an intervention group and control group was larger in early infancy than later in the first year of life. Late discordance such as that in the present study may be common in studies with an observational design. The brain is more sensitive to environmental factors earlier in life; therefore, the discordance later in life may produce less divergent impacts on brain development between siblings. This factor may explain, at least partially, the null results of sibling comparison in previous observational studies. ${ }^{915} 16$

\section{Strengths and limitations}

To our knowledge, this study is the largest birth cohort study examining the association between breast feeding and brain

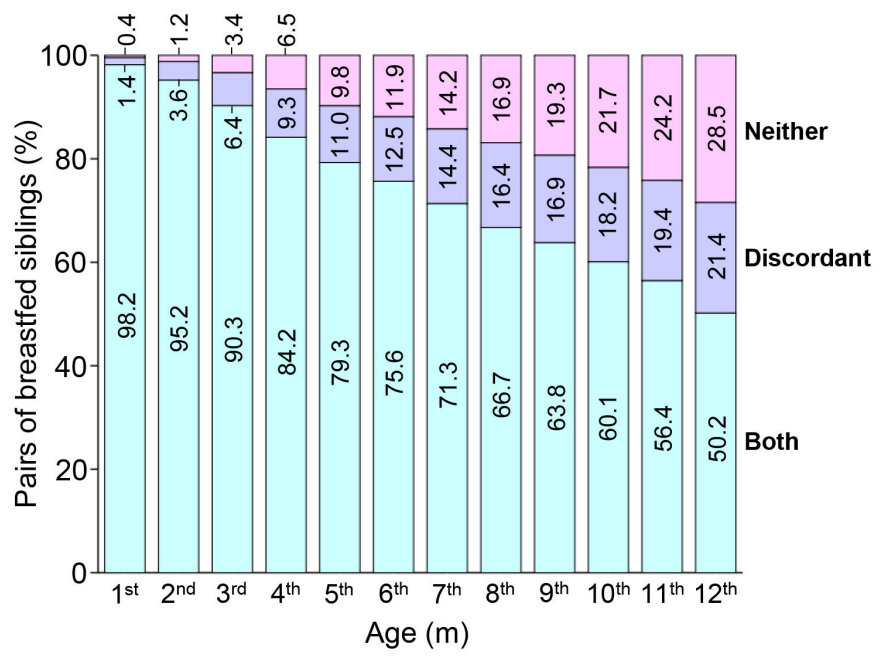

Figure 2 Pairs of siblings who were both breastfed, discordantly breastfed or neither breastfed with respect to each month of life $(n=3117)$. function. We conducted sibling pair analyses with a sufficient number of participants from this large cohort, which enabled us to have strong control over sibling-shared parental and environmental factors. Monthly information on feeding methods was precisely obtained via successive questionnaires at 1 month, 6 months and 12 months old, which yielded a much smaller risk of recall bias than that of previous sibling pair studies. ${ }^{91516}$

The current study does have several limitations. The information was largely obtained from self-administered questionnaires. In particular, the identified developmental delay may be somewhat equivocal because it relied solely on responses on the parent-reported screening test of Japanese version of ASQ. Furthermore, even in sibling pair analysis, other confounding factors such as environmental factors may be responsible for the differences because siblings do not share all environmental factors and shared environments may not always be stable. ${ }^{17}$ Finally, there were no data on what factors have contributed to cessation of breast feeding. Even within a pair of sibling, there could be difference in socioeconomical status, which might alter parent's rearing behaviours and then affect the child's development. If an infant at potential risk of developmental disorders has less preference to breast feeding, a superficial association can be produced between breast feeding and better development. Indeed, a metaanalysis demonstrated altered feeding habits in children with attention-deficit/hyperactivity disorder. ${ }^{52}$ Although our supplementary analyses rather argued against such possibility, the association between breast feeding and a reduced risk of developmental delay in our study still could be explained by such reverse causation.

\section{CONCLUSION}

The present study demonstrated for the first time, by using sibling pair analysis, an association of continuous breast feeding with reduced developmental delay at 1 year. Although causal inference should be cautious in observational studies, both the prospective longitudinal and family-based matched analyses presented may provide a 
more persuasive argument for public health practitioners and policy-makers to promote breastfeeding continuation, at least during the first year of life. The ongoing JECS cohort may reveal how long the observed beneficial effects will persist in later life.

\section{Author affiliations}

${ }^{1}$ Research Center for Environment and Developmental Medical Sciences, Kyushu University, Fukuoka, Japan

${ }^{2}$ Department of Pediatrics, Graduate School of Medical Sciences, Kyushu University, Fukuoka, Japan

${ }^{3}$ Department of Pediatrics, University of Occupational and Environmental Health, Kitakyushu, Japan

${ }^{4}$ Regional Center for Japan Environment and Children's Study, University of Occupational and Environmental Health, Kitakyushu, Japan

${ }^{5}$ Department of Obstetrics and Gynecology, Graduate School of Medical Sciences, Kyushu University, Fukuoka, Japan

${ }^{6}$ Department of Pediatrics, National Hospital Organization Fukuoka National Hospital, Fukuoka, Japan

Acknowledgements We thank all participants of the JECS and all staff members involved in data collection.

Collaborators Japan Environment and Children's Study Group.Members of the JECS Group as of 2021: Michihiro Kamijima (principal investigator; Nagoya City University, Nagoya, Japan), Shin Yamazaki (National Institute for Environmental Studies, Tsukuba, Japan), Yukihiro Ohya (National Center for Child Health and Development, Tokyo, Japan), Reiko Kishi (Hokkaido University, Sapporo, Japan), Nobuo Yaegashi (Tohoku University, Sendai, Japan), Koichi Hashimoto (Fukushima Medical University, Fukushima, Japan), Chisato Mori (Chiba University, Chiba, Japan), Shuichi Ito (Yokohama City University, Yokohama, Japan), Zentaro Yamagata (University of Yamanashi, Chuo, Japan), Hidekuni Inadera (University of Toyama, Toyama, Japan), Takeo Nakayama (Kyoto University, Kyoto, Japan), Hiroyasu Iso (Osaka University, Suita, Japan), Masayuki Shima (Hyogo College of Medicine, Nishinomiya, Japan), Youichi Kurozawa (Tottori University, Yonago, Japan), Narufumi Suganuma (Kochi University, Nankoku, Japan), Koichi Kusuhara (University of Occupational and Environmental Health, Kitakyushu, Japan), and Takahiko Katoh (Kumamoto University, Kumamoto, Japan).

Contributors MSa conceived, designed the study, analysed the data, interpreted the results and wrote the manuscript. AS, MSh and MO interpreted the results and critically reviewed the manuscript. YSo, MT, YI, RS and YSa critically reviewed the manuscript. SH analysed the data, interpreted the results and critically reviewed the manuscript. KK and SO directed the study and critically reviewed the manuscript.

Funding The Japan Environment and Children's Study and the present study were entirely funded by the Ministry of the Environment, Japan (No.1804171).

Disclaimer The findings and conclusions of this article are the sole responsibility of the authors and do not represent the official views of the Japanese government.

Competing interests Dr MSa and Professor SO received a grant and director's fees, respectively, from Morinaga Houshikai outside of the submitted work. The other authors have no conflicts of interest relevant to this article to disclose.

Patient consent for publication Not required.

Ethics approval The JECS protocol was reviewed and approved by the Ministry of Environment's Institutional Review Board for Epidemiological Studies and by the ethics committees of all participating institutions (No.100910001). The ethical approval for this study was an extension of the ethical approval for the JECS protocol. Written informed consent was obtained from all parents.

Provenance and peer review Not commissioned; externally peer reviewed.

Data availability statement Data are unsuitable for public deposition due to ethical restrictions and legal framework of Japan. For details, see http://www.env. go.jp/chemi/ceh/en/. All inquiries about access to data should be sent to: jecsen@nies.go.jp. The person responsible for handling enquiries sent to this e-mail address is Dr Shoji F. Nakayama, JECS Programme Office, National Institute for Environmental Studies. No data are available. For details, see http://www.env.go.jp/ chemi/ceh/en/.

Supplemental material This content has been supplied by the author(s). It has not been vetted by BMJ Publishing Group Limited (BMJ) and may not have been peer-reviewed. Any opinions or recommendations discussed are solely those of the author(s) and are not endorsed by BMJ. BMJ disclaims all liability and responsibility arising from any reliance placed on the content. Where the content includes any translated material, BMJ does not warrant the accuracy and reliability of the translations (including but not limited to local regulations, clinical guidelines, terminology, drug names and drug dosages), and is not responsible for any error and/or omissions arising from translation and adaptation or otherwise.

Open access This is an open access article distributed in accordance with the Creative Commons Attribution Non Commercial (CC BY-NC 4.0) license, which permits others to distribute, remix, adapt, build upon this work non-commercially, and license their derivative works on different terms, provided the original work is properly cited, appropriate credit is given, any changes made indicated, and the use is non-commercial. See: http://creativecommons.org/licenses/by-nc/4.0/.

\section{ORCID iDs}

Masafumi Sanefuji http://orcid.org/0000-0001-6036-5528

Yasunari Sakai http://orcid.org/0000-0002-5747-8692

\section{REFERENCES}

1 Hoefer C, Hardy MC. Later development of breast fed and artifically fed infants: comparison of physical and mental growth. JAMA 1929;92:615-9.

2 Horta BL, victora CG. Long-term effects of breastfeeding: a systematic review. Geneva: Wolrd Health Organization, 2013.

3 Horta BL, Loret de Mola C, Victora CG. Breastfeeding and intelligence: a systematic review and meta-analysis. Acta Paediatr 2015;104:14-19.

4 Anderson JW, Johnstone BM, Remley DT. Breast-feeding and cognitive development: a meta-analysis. Am J Clin Nutr 1999:70:525-35.

5 Morrow-Tlucak M, Haude RH, Ernhart CB. Breastfeeding and cognitive development in the first 2 years of life. Soc Sci Med 1988;26:635-9.

6 Whitehouse AJO, Robinson M, Li J, et al. Duration of breast feeding and language ability in middle childhood. Paediatr Perinat Epidemiol 2011;25:44-52.

7 Victora CG, Horta BL, Loret de Mola C, et al. Association between breastfeeding and intelligence, educational attainment, and income at 30 years of age: a prospective birth cohort study from Brazil. Lancet Glob Health 2015;3:e199-205.

8 Strøm M, Mortensen EL, Kesmodel US, et al. Is breast feeding associated with offspring IQ at age 5 ? Findings from prospective cohort: lifestyle during pregnancy study. BMJ Open 2019;9:e023134.

9 Der G, Batty GD, Deary IJ. Effect of breast feeding on intelligence in children: prospective study, sibling pairs analysis, and meta-analysis. BMJ 2006;333:945.

10 Singh GK, Kogan MD, Dee DL. Nativity/immigrant status, race/ ethnicity, and socioeconomic determinants of breastfeeding initiation and duration in the United States, 2003. Pediatrics 2007;119:S38-46.

11 van Rossem L, Oenema A, Steegers EAP, et al. Are starting and continuing breastfeeding related to educational background? The generation R study. Pediatrics 2009;123:e1017-27.

12 Brion M-JA, Lawlor DA, Matijasevich A, et al. What are the causal effects of breastfeeding on IQ, obesity and blood pressure? Evidence from comparing high-income with middle-income cohorts. Int $J$ Epidemiol 2011;40:670-80.

13 Gibson-Davis CM, Brooks-Gunn J. Breastfeeding and verbal ability of 3-year-olds in a multicity sample. Pediatrics 2006;118:e1444-51.

14 Belfort MB, Rifas-Shiman SL, Kleinman KP, et al. Infant feeding and childhood cognition at ages 3 and 7 years: effects of breastfeeding duration and exclusivity. JAMA Pediatr 2013;167:836-44.

15 Evenhouse E, Reilly S. Improved estimates of the benefits of breastfeeding using sibling comparisons to reduce selection bias. Health Serv Res 2005;40:1781-802.

16 Colen CG, Ramey DM. Is breast truly best? Estimating the effects of breastfeeding on long-term child health and wellbeing in the United States using sibling comparisons. Soc Sci Med 2014;109:55-65.

17 Smithers LG, Kramer MS, Lynch JW. Effects of breastfeeding on obesity and intelligence: causal insights from different study designs. JAMA Pediatr 2015;169:707-8.

18 Yang S, Martin RM, Oken E, et al. Breastfeeding during infancy and neurocognitive function in adolescence: 16 -year follow-up of the PROBIT cluster-randomized trial. PLoS Med 2018;15:e1002554.

19 Kawamoto T, Nitta H, Murata K, et al. Rationale and study design of the Japan environment and children's study (JECS). BMC Public Health 2014;14:25. 
20 Michikawa T, Nitta H, Nakayama SF, et al. Baseline profile of participants in the Japan environment and children's study (JECS). J Epidemiol 2018;28:99-104.

21 Squires J, Elizabeth T, Bricker D. ASQ-3 user's guide. Baltimore: Brookes Publishing, 2009.

22 Limbos MM, Joyce DP. Comparison of the ASQ and PEDS in screening for developmental delay in children presenting for primary care. J Dev Behav Pediatr 2011;32:499-511.

23 Schonhaut L, Armijo I, Schönstedt M, et al. Validity of the ages and stages questionnaires in term and preterm infants. Pediatrics 2013;131:e1468-74.

24 Lopes S, Graça P, Teixeira S, et al. Psychometric properties and validation of Portuguese version of ages \& stages questionnaires (3rd edition): 9,18 and 30 questionnaires. Early Hum Dev 2015:91:527-33.

25 Bernard JY, De Agostini M, Forhan A, et al. Breastfeeding duration and cognitive development at 2 and 3 years of age in the EDEN mother-child cohort. J Pediatr 2013;163:36-42.

26 Filgueiras A, Pires P, Maissonette S, et al. Psychometric properties of the Brazilian-adapted version of the ages and stages questionnaire in public child daycare centers. Early Hum Dev 2013;89:561-76.

27 Srinithiwat B, Ularntinon S. Concurrent validity of the ages \& stages questionnaires, Third Edition, Thai-version (ASQ-3 Thai) with the denver developmental screening test II (DDST-II) in developmental screening of 18,24 , and 30 months old children at Queen Sirikit National Institute of Child Health. J Med Assoc Thai 2014:97:S6-13.

28 Mezawa H, Aoki S, Nakayama SF, et al. Psychometric profile of the ages and stages questionnaires, Japanese translation. Pediatr Int 2019;61:1086-95.

29 Caldwell BM, Bradley RH. Home observation for measurement of the environment. Little Rock, AR: University of Arkansas, 1984.

30 Sjolander A, Johansson ALV, Lundholm C. Analysis of 1:1 matched cohort studies and twin studies, with binary exposures and binary outcomes. Stat Sci 2012;27:395-411.

31 Zhang J, Yu KF. What's the relative risk? A method of correcting the odds ratio in cohort studies of common outcomes. JAMA 1998;280:1690-1.

32 Wang Z. Converting odds ratio to relative risk in cohort studies with partial data information. J Stat Softw 2013;55:5.

33 Kramer MS, Aboud F, Mironova E, et al. Breastfeeding and child cognitive development: new evidence from a large randomized trial. Arch Gen Psychiatry 2008;65:578-84.

34 Martin CR, Ling P-R, Blackburn GL. Review of infant feeding: key features of breast milk and infant formula. Nutrients 2016;8:279.

35 Victora CG, Bahl R, Barros AJD, et al. Breastfeeding in the 21st century: epidemiology, mechanisms, and lifelong effect. Lancet 2016;387:475-90.

36 Brown Belfort M, Belfort MB. The science of breastfeeding and brain development. Breastfeed Med 2017;12:459-61.

37 Beebe B, Myers MM, Lee SH, et al. Family nurture intervention for preterm infants facilitates positive mother-infant face-to-face engagement at 4 months. Dev Psychol 2018;54:2016-31.
38 Hane AA, LaCoursiere JN, Mitsuyama M, et al. The Welch emotional connection screen: validation of a brief mother-infant relational health screen. Acta Paediatr 2019;108:615-25.

39 Hane AA, Myers MM, Hofer MA, et al. Family nurture intervention improves the quality of maternal caregiving in the neonatal intensive care unit: evidence from a randomized controlled trial. J Dev Behav Pediatr 2015;36:188-96.

40 Porges SW, Davila MI, Lewis GF, et al. Autonomic regulation of preterm infants is enhanced by family nurture intervention. Dev Psychobiol 2019;61:942-52.

41 Welch MG, Barone JL, Porges SW, et al. Family nurture intervention in the NICU increases autonomic regulation in mothers and children at 4-5 years of age: follow-up results from a randomized controlled trial. PLoS One 2020:15:e0236930.

42 Welch MG, Firestein MR, Austin J, et al. Family nurture intervention in the neonatal intensive care unit improves social-relatedness, attention, and neurodevelopment of preterm infants at 18 months in a randomized controlled trial. $J$ Child Psychol Psychiatry 2015;56:1202-11.

43 Welch MG, Halperin MS, Austin J, et al. Depression and anxiety symptoms of mothers of preterm infants are decreased at 4 months corrected age with family nurture intervention in the NICU. Arch Womens Ment Health 2016;19:51-61.

44 Ludwig RJ, Welch MG. How babies learn: the autonomic socioemotional reflex. Early Hum Dev 2020;151:105183.

45 Vestergaard M, Obel C, Henriksen TB, et al. Duration of breastfeeding and developmental milestones during the latter half of infancy. Acta Paediatr 1999;88:1327-32.

46 Thorsdottir I, Gunnarsdottir I, Kvaran MA, et al. Maternal body mass index, duration of exclusive breastfeeding and children's developmental status at the age of 6 years. Eur $J$ Clin Nutr 2005;59:426-31.

47 Eickmann SH, de Lira PIC, Lima MD. Breast feeding and mental and motor development at 12 months in a low-income population in northeast Brazil. Paediatr Perinat Ep 2007;21:129-37.

48 Tozzi AE, Bisiacchi P, Tarantino V, et al. Effect of duration of breastfeeding on neuropsychological development at 10 to 12 years of age in a cohort of healthy children. Dev Med Child Neurol 2012;54:843-8.

49 Jonsdottir OH, Thorsdottir I, Gunnlaugsson G, et al. Exclusive breastfeeding and developmental and behavioral status in early childhood. Nutrients 2013;5:4414-28.

50 Anjos T, Altmäe S, Emmett P, et al. Nutrition and neurodevelopment in children: focus on NUTRIMENTHE project. Eur $J$ Nutr 2013:52:1825-42.

51 Fewtrell MS, Morgan JB, Duggan C, et al. Optimal duration of exclusive breastfeeding: what is the evidence to support current recommendations? Am J Clin Nutr 2007;85:635S-8.

52 Tseng P-T, Yen C-F, Chen Y-W, et al. Maternal breastfeeding and attention-deficit/hyperactivity disorder in children: a meta-analysis. Eur Child Adolesc Psychiatry 2019;28:19-30. 